\title{
Progressive hydrocephalus despite early complete reversal of hindbrain herniation after prenatal open myelomeningocele repair
}

\author{
Victor M. Lu, MBBS, PhD, ${ }^{1}$ Kendall A. Snyder, MD, ${ }^{1}$ Eniola R. Ibirogba, MBBS, ${ }^{2}$ \\ Rodrigo Ruano, MD, PhD, ${ }^{2}$ David J. Daniels, MD, PhD, ${ }^{1}$ and Edward S. Ahn, MD ${ }^{1}$ \\ 1Department of Neurosurgery and 2Division of Maternal-Fetal Medicine, Department of Obstetrics and Gynecology, Mayo Clinic, \\ Rochester, Minnesota
}

\begin{abstract}
OBJECTIVE Open prenatal myelomeningocele (MMC) repair is typically associated with reversal of in utero hindbrain herniation $(\mathrm{HBH})$ and has been posited to be associated with a reduction in both postoperative prenatal and immediate postnatal hydrocephalus (HCP) risks. However, the long-term postnatal risk of HCP following HBH reversal in these cases has not been well defined. The authors describe the results of a long-term HCP surveillance in a cohort of patients who underwent prenatal MMC repair at their institution.
\end{abstract}

METHODS A retrospective review of all prenatal MMC repair operations performed at the Mayo Clinic between 2012 and 2017 was conducted. Pertinent data regarding the clinical courses of these patients before and after MMC repair were summarized. Outcomes of interest were occurrences of $\mathrm{HBH}$ and $\mathrm{HCP}$ and the need for intervention.

RESULTS A total of 9 prenatal MMC repair cases were identified. There were 7 cases in which MRI clearly demonstrated prenatal $\mathrm{HBH}$, and of these $86 \%(6 / 7)$ had evidence of $\mathrm{HBH}$ reversal after repair and prior to delivery. After a mean postnatal follow-up of 20 months, there were 3 cases of postnatal HCP requiring intervention. One case that failed to show complete $\mathrm{HBH}$ reversal after MMC repair required early ventriculoperitoneal shunting. The other 2 cases were of progressive, gradual-onset HCP despite complete prenatal $\mathrm{HBH}$ reversal, requiring endoscopic third ventriculostomy with choroid plexus cauterization at ages 5 and 7 months.

CONCLUSIONS Although prenatal MMC repair can achieve HBH reversal in a majority of well-selected cases, the prevention of postnatal HCP requiring intervention appears not to be predicated on this outcome alone. In fact, it appears that in a subset of cases in which HBH reversal is achieved, patients can experience a progressive, gradual-onset HCP within the 1st year of life. These findings support continued rigorous postnatal surveillance of all prenatal MMC repair patients, irrespective of postoperative HBH outcome.

https://thejns.org/doi/abs/10.3171/2019.7.FOCUS19434

KEYWORDS myelomeningocele; spina bifida; hydrocephalus; hindbrain herniation; reversal; open repair

$\mathrm{N}$ EURAL tube defects are the most common congenital central nervous system anomaly compatible with life. ${ }^{9}$ The most frequent defect is myelomeningocele (MMC), otherwise termed spina bifida, which is an open skin defect characterized by a cleft in the vertebral column that exposes the meninges and spinal cord, occurring in approximately $0.3-1$ per 1000 live births. ${ }^{5,9}$ It is hypothesized that leakage of CSF via the skin defect can result in intracranial hypotension leading to a constellation of Chiari type II anomalies, including hindbrain herniation $(\mathrm{HBH}))^{8,11,16,25}$ These anomalies can cause prenatal and postnatal obstruction of the intracranial CSF circulation, resulting in hydrocephalus (HCP). ${ }^{9}$ Failure to alleviate HBH burden and minimize HCP risk can lead to motor, autonomic, and cognitive deficits in utero, as well as to a sizeable mortality risk in neonates by delivery. ${ }^{5,18}$

Historically, the treatment of MMCs was reserved until after delivery, when repair by defect closure could be

ABBREVIATIONS EGA = estimated gestational age; ETVICPC = endoscopic third ventriculostomy with choroid plexus cauterization; $\mathrm{HBH}=$ hindbrain herniation; $\mathrm{HCP}=$ hydrocephalus; $\mathrm{MMC}=$ myelomeningocele; $\mathrm{MOMS}=$ Management of Myelomeningocele Study; $\mathrm{VP}=$ ventriculoperitoneal.

SUBMITTED May 30, 2019. ACCEPTED July 26, 2019.

INCLUDE WHEN CITING DOI: 10.3171/2019.7.FOCUS19434. 
achieved. Any arising HCP was treated using a ventriculoperitoneal (VP) shunt system, and more recently, endoscopic third ventriculostomy with choroid plexus cauterization (ETV/CPC) has emerged as an additional alternative.,15 By the early 2000s, prenatal MMC repair by means of hysterotomy emerged as a possible alternative to the postnatal management of MMC defects. ${ }^{22,23}$ The possible benefit was that neurological function could be preserved earlier, in part due to the earlier reversal of $\mathrm{HBH}$ and reduction of HCP risk and other developmental sequelae. ${ }^{13,17,20}$ The Management of Myelomeningocele Study (MOMS) ${ }^{1}$ in the early 2010s demonstrated in a randomized fashion that prenatal MMC repair resulted in a significantly favorable greater incidence of mild to zero $\mathrm{HBH}$ after delivery when compared to postnatal MMC repair (75\% vs 33\%) and that the requirement of VP shunting for HCP was significantly reduced following prenatal versus postnatal repair (40\% vs $88 \%)$.

To date, evaluation of prenatal MMC repair has not focused specifically on the postnatal neurological outcomes of those in whom complete HBH reversal is successfully achieved in the post-MOMS era. Although residual HBH after prenatal MMC repair has been strongly linked to increased postnatal HCP risk, it has not been thoroughly explored if complete $\mathrm{HBH}$ reversal eliminates postnatal HCP risk altogether. ${ }^{3,26}$ Such an understanding would guide and support the nature of surveillance for HCP in this era of increasing numbers of infants who have undergone prenatal MMC repair. Correspondingly, the aim of this study was to summarize the experience of a single institution with prenatal MMC repair focusing on the postnatal HCP outcomes of prenatal MMC repair cases with complete $\mathrm{HBH}$ reversal.

\section{Methods \\ Study Population}

An institutional database was retrospectively interrogated for all prenatal MMC repair procedures between January 2012 and December 2017 performed by the Departments of Neurosurgery and Obstetrics and Gynecology at our institution. Inclusion criteria for our open fetal surgical repair of MMC were similar to those of the MOMS trial: ${ }^{1}$ a radiological indication of $\mathrm{HBH}$, with pre- and postoperative images to assess $\mathrm{HBH}$ course, singleton pregnancy, upper boundary of MMC located between T1 and S1, estimated gestational age (EGA) between $20+0$ and $26+0$ at time of repair, in fetuses with normal karyotype by invasive testing (amniocentesis or chorionic villus sampling), and in mothers age older than 18 years. Exclusion criteria included fetal anomalies unrelated to MMC, severe spinal deformity, increased risk of preterm birth due to short cervix, placental abruption, and a history of hysterotomy in the active uterine segment. The present study was approved by the Mayo Clinic institutional review board.

\section{Procedure}

After obtaining consent, all patients proceeded with preoperative workup, including fetal echocardiography, and imaging with ultrasound and MRI. Prior to the start of the procedure, steroids, tocolytics, and antibiotics were administered. Open MMC repair was then performed via a hysterotomy approach as described in the MOMS trial. ${ }^{1}$ After discharge, patients were followed with weekly ultrasounds at the maternal-fetal medicine clinic until delivery.

\section{Outcomes}

A pediatric neurosurgeon blinded to operative and postnatal outcomes evaluated HBH by inspection of preoperative, postoperative, and postnatal MR images and review of radiology reports. HBH was defined as a downward displacement of the medulla, fourth ventricle, and cerebellar vermis into the spinal canal below the level of the foramen magnum, with possible brainstem compression, low-lying venous sinuses, and a small posterior fossa. ${ }^{8,25}$ The need for any HCP intervention was multidisciplinary, and the decision to proceed was decided by a pediatric neurosurgeon in consensus with another clinical specialist based on imaging results and clinical presentation. HCP was defined by clinical signs of increased intracranial CSF pressures and by radiological evidence of progressive ventriculomegaly. Intervention was by either VP shunt placement or ETV/ $\mathrm{CPC}$ at the discretion of the neurosurgeon.

\section{Results \\ Demographics}

A total of 9 consecutive fetuses ( 8 females, 1 male) underwent prenatal MMC repair via a hysterotomy during the study period, and there was sufficient imaging data for prenatal and postnatal $\mathrm{HBH}$ assessment (Table 1). The median age of the mothers and the EGA of the patients at time of MMC repair were 31 years (range 24-36 years) and $25+2$ weeks (i.e., weeks + days) (range $23+3$ to $26+0$ weeks), respectively. All procedures were tolerated without complication. The median EGA at delivery was $36+0$ weeks (range $31+2$ to $37+2$ weeks). The mean follow-up period was 20 months (range 1-50 months) after delivery.

\section{Clinical Outcomes}

Of the 9 patients, 7 (78\%) were found to show clear MRI-detected evidence of $\mathrm{HBH}$ at time of prenatal MMC repair, with lesions located between L2 and L5. The other 2 patients had HBH indications on their prenatal sonography but not on their MRI. In one of the 2 patients, the posterior fossa was not well visualized on the preoperative MR image, so HBH was not definitively present. Following surgical intervention, in utero MRI demonstrated evidence of prenatal HBH reversal in $6(86 \%)$ of the 7 previously definitive cases. The one outstanding case was the only case of 6 fetuses showing signs of prenatal HCP/ ventriculomegaly that did not resolve after surgery.

All fetuses were successfully delivered without complication. By the last follow-up, of the 9 cases, 3 patients (33\%) with postnatal HCP required treatment: 1 patient who did not show complete HBH reversal and who developed immediate postnatal HCP, and 2 patients with evidence of complete $\mathrm{HBH}$ reversal in whom gradual-onset postnatal HCP developed. The clinical courses of these 3 patients are described below. 
TABLE 1. Clinical features of all included patients

\begin{tabular}{|c|c|c|c|c|c|c|c|c|c|c|}
\hline \multirow{2}{*}{$\begin{array}{l}\text { Case } \\
\text { No. }\end{array}$} & \multirow{2}{*}{$\begin{array}{l}\text { Mother's } \\
\text { Age (yrs) }\end{array}$} & \multirow{2}{*}{$\begin{array}{l}\text { Pt } \\
\text { Sex }\end{array}$} & \multicolumn{2}{|c|}{ EGA (wks + days) } & \multicolumn{3}{|c|}{ Prenatal Preop Findings } & \multirow{2}{*}{$\begin{array}{c}\text { Prenatal } \\
\text { Postop HBH }\end{array}$} & \multicolumn{2}{|c|}{ Postnatal Course } \\
\hline & & & At Op & At Delivery & $\mathrm{HBH}$ & HCP/VM & Level of Lesion & & $\mathrm{HCP}$ & Intervention \\
\hline 1 & 24 & $\mathrm{~F}$ & $23+3$ & $37+0$ & Yes & No & L5 & No & No & No \\
\hline 2 & 35 & $\mathrm{~F}$ & $25+2$ & $32+1$ & $\mathrm{No}^{*}$ & Yes & L3 & No & No & No \\
\hline 3 & 31 & $\mathrm{~F}$ & $25+2$ & $31+2$ & Yes & No & L5 & No & No & No \\
\hline 4 & 31 & $\mathrm{~F}$ & $25+4$ & $31+2$ & Yes & Yes & L2 & No & Gradual & ETVICPC \\
\hline 5 & 36 & $\mathrm{~F}$ & $24+2$ & $37+2$ & Yes & Yes & L3 & No & No & No \\
\hline 6 & 26 & $\mathrm{~F}$ & $26+1$ & $36+0$ & Yes & Yes & L4 & No & No & No \\
\hline 7 & 35 & $\mathrm{~F}$ & $25+3$ & $32+3$ & Yes & Yes & L2 & No & Gradual & ETV/CPC \\
\hline 8 & 27 & $M$ & $25+1$ & $36+0$ & $\mathrm{No}^{*}$ & No & L2 & No & No & No \\
\hline 9 & 26 & $\mathrm{~F}$ & $24+2$ & $36+2$ & Yes & Yes & L2 & Yes & Immediate & VP shunt \\
\hline
\end{tabular}

$\mathrm{Pt}=$ patient $; \mathrm{VM}=$ ventriculomegaly.

* Indeterminate on MRI but suggestive on ultrasound.

\section{Immediate Postnatal HCP After No Prenatal HBH Reversal Case 1}

A female fetus failed to show HBH reversal after prenatal L2 MMC repair at EGA $23+0$ weeks (Fig. 1). We observed ventriculomegaly on prenatal imaging, and persistent $\mathrm{HBH}$ on postnatal imaging after delivery at EGA $36+4$ weeks. The patient showed signs of increasing head circumference and upgaze palsy, without any signs of lower brainstem dysfunction. Ultimately the decision was made 1 month after delivery to insert a VP shunt. Her clinical course was unremarkable at last follow-up 3 years later.

\section{Gradual-Onset Postnatal HCP After Complete Prenatal HBH Reversal}

Case 2

A female fetus underwent L2 MMC repair at EGA $22+1$ weeks with evidence of prenatal $\mathrm{HBH}$ reversal by EGA 31 weeks (Fig. 2). However, by 4 months after delivery, ventriculomegaly was observed. There was a gradual increase in extent of ventriculomegaly, accompanied by an enlarging head circumference at 7 months after delivery, without any signs of lower brainstem dysfunction. The decision to pursue ETV/CPC was made at the time when imaging was suggestive of, but indeterminate for, aqueductal stenosis. This patient did not require any further treatment at that time, and her clinical course was unremarkable at her last follow-up 1 year later.

\section{Case 3}

Similarly, another female fetus underwent L2 MMC repair at EGA $23+0$ weeks, with evidence of prenatal $\mathrm{HBH}$ resolution at EGA 33 weeks (Fig. 3). However, by 3 months after delivery, ventriculomegaly was observed. There was a gradual increase in the extent of ventriculomegaly accompanied by enlarging head circumference and upgaze palsy at 5 months after delivery, without any signs of lower brainstem dysfunction. The decision to pursue ETV/CPC was made at the time when imaging was suggestive of, but indeterminate for, aqueductal stenosis. This patient did not require any further treatment at that time, and her clinical course was unremarkable at last follow-up 4 years later.

\section{Discussion}

In our series, we detail the novel observation of progressive HCP that occurs despite prenatal complete HBH reversal after MMC repair. This finding occurred despite the association between postnatal HCP evolution and partial prenatal HBH reversal being well documented both before and after delivery. ${ }^{12}$ Therefore, the assumptive association between prenatal $\mathrm{HBH}$ reversal and the prevention of postnatal HCP may be premature. As we continue to develop

Pre-op/-natal EGA 23+0 wks

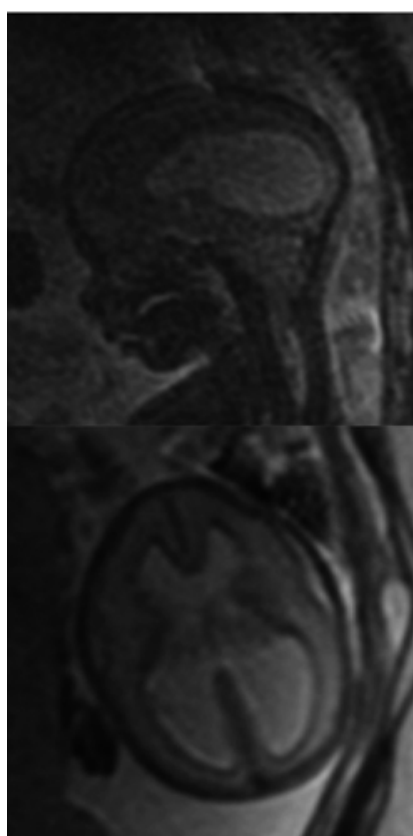

FIG. 1. Case 1. Studies obtained in a female fetus that failed to show postoperative $\mathrm{HBH}$ reversal after prenatal MMC repair at an EGA of $23+0$ weeks, with subsequent development of immediate-onset postnatal HCP, syringomyelia, and head circumference $(\mathrm{HC})$ enlargement requiring the early placement of a VP shunt. 
Pre-op/-natal

EGA 22+1 wks

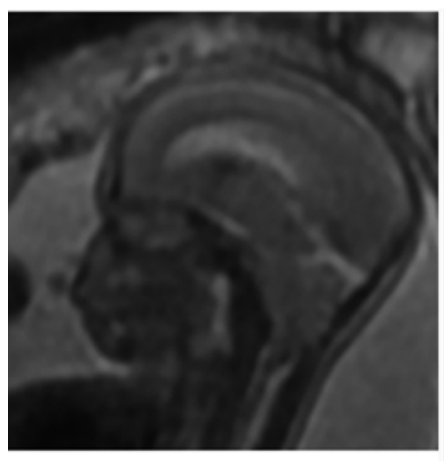

Post-op/-natal

EGA $31+0$ wks

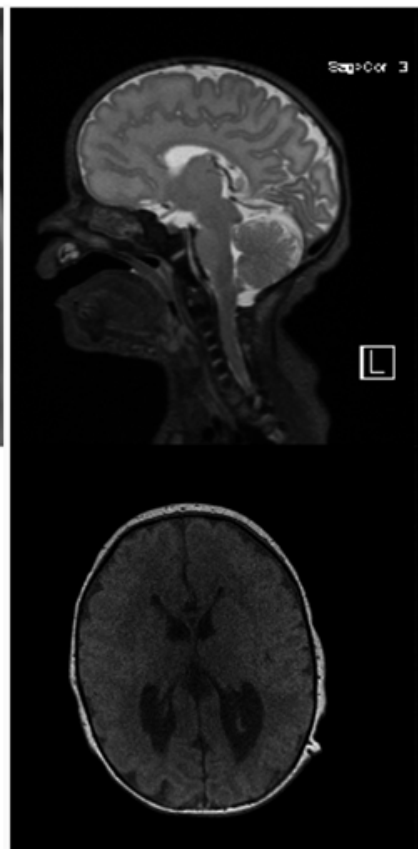

Postnatal

4 months

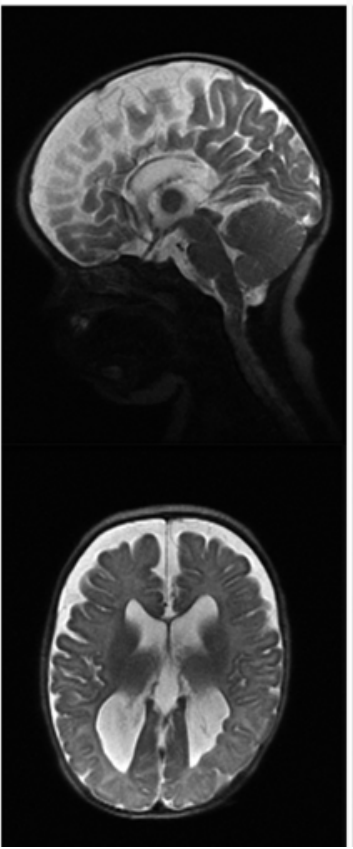

Postnatal

7 months

Enlarging $\mathrm{HC}$ ETV-CPC

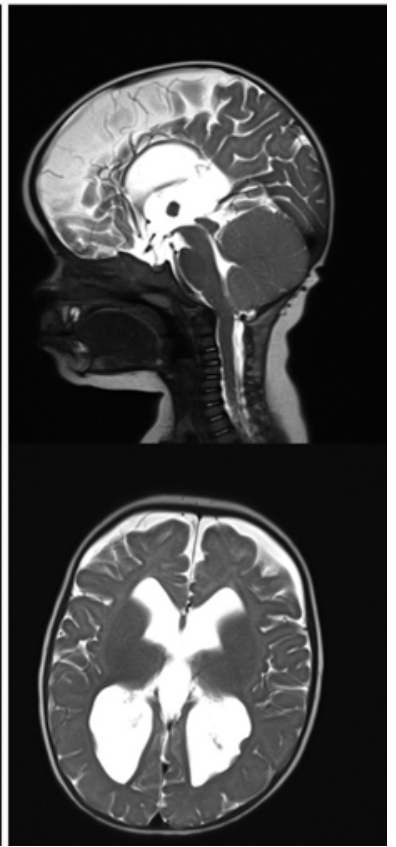

FIG. 2. Case 2. Studies acquired in a female fetus that showed postoperative HBH reversal after prenatal MMC repair at an EGA of $22+1$ weeks, with subsequent development of gradual-onset postnatal HCP and head circumference enlargement, requiring ETV/CPC at 7 months of age.

prenatal surgery for MMCs, gradual-onset HCP remains a nonnegligible sequela of successful $\mathrm{HBH}$ reversal with prenatal intervention.

The MOMS trial ${ }^{1}$ demonstrated that prenatal MMC repair resulted in significantly greater incidence of mild to absent HBH after birth compared to postnatal MMC repair $(75 \%$ vs $33 \%)$. Of our 7 patients with definitive $\mathrm{HBH}$, $6(86 \%)$ had $\mathrm{HBH}$ resolution at birth, which is largely congruent with that prenatal component of the MOMS experience, ${ }^{1}$ as well as other post-MOMS experiences, ${ }^{19}$ ranging from $71 \%$ to $81 \%$. However, one of the shortcomings of the MOMS and subsequent trials was that they did not further detail the clinical course of those prenatal subjects who experienced prenatal HBH resolution. In fact, this aspect has been a large deficiency in many of the post-MOMS experiences that have been reported since. Recently, Zarutskie et al. ${ }^{26}$ alluded to this question in their series of 44 MMC prenatal repairs. They reported on 14 cases (32\%) in which HCP intervention was ultimately required, a proportion similar to our study. Of the 14, 12 had evidence of postoperative prenatal residual $\mathrm{HBH}$. Therefore, there were 2 outstanding cases of confirmed prenatal HBH resolution that still required postnatal HCP intervention. Although they did not further explore this unique subcohort, its presence supports the observations in our series that such a subcohort exists.

Our first case illustrates that should there be residual $\mathrm{HBH}$ after surgery, then the HCP can be persistent and require immediate treatment after delivery. The acuteness of this occurrence has been implied in a post-MOMS experience already,$^{10}$ which is not particularly surprising as residual HBH has been shown to significantly predict postnatal HCP evolution. 2,3,26 Nevertheless, our latter 2 cases underscore the previously poorly reported phenomenon where, despite complete postoperative prenatal HBH resolution, there is a risk of postnatal HCP with gradual onset and progression. These infants did not display any clinical signs of lower brainstem compression. In cases in which such concerns for compression exist, sleep and swallow studies could be useful in determining the residual effect of $\mathrm{HBH}$.

The mechanism by which this late HCP occurs in the context of complete HBH resolution following prenatal MMC repair is not clear. Traditionally, it is believed that prenatal MMC repair affects the CSF hydrodynamics, which then accommodate HBH reversal in utero. ${ }^{4,16}$ However, there is evidence to suggest, at least in the postnatal setting, that preoperative ventriculomegaly may not be completely reversed after MMC repair, which leaves open the possibility that increased ventricular size, despite surgery, may still predispose a patient to HCP development regardless of $\mathrm{HBH}$ status after birth. ${ }^{22}$ The physiology of CSF hydrodynamics before and after fetus delivery is an area that has not been widely investigated, and as such, it remains a distinct possibility that hydrodynamic changes after delivery may synergize with potential anatomical predispositions for postnatal HCP induced by the prenatal MMC, independent of its repair. One such possibility 


\section{Pre-op/-natal \\ EGA 23+0 wks \\ Post-op/-natal \\ EGA 33+0 wks \\ Postnatal 3 months}

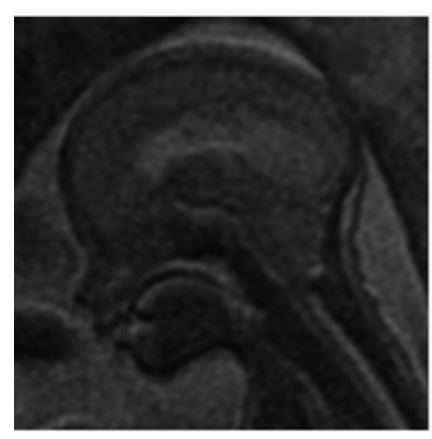

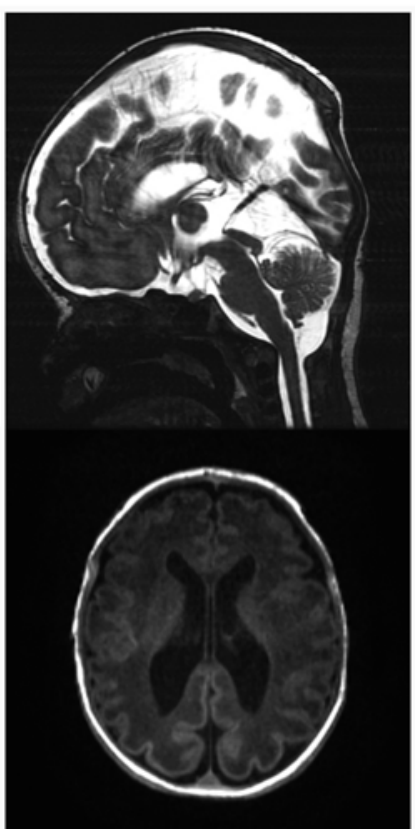

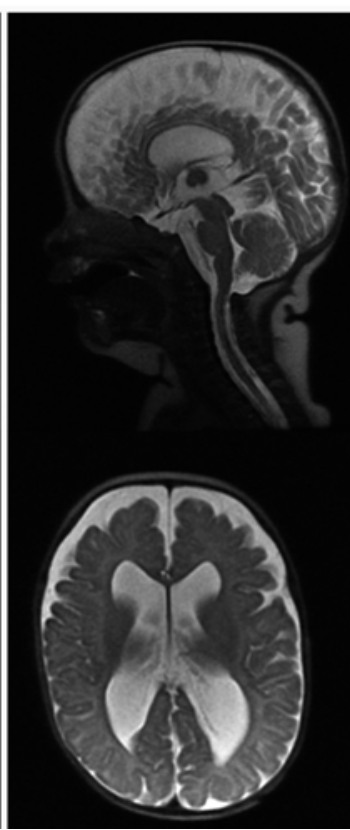

Postnatal 5 months

Enlarging $\mathrm{HC}$, upgaze palsy ETV-CPC

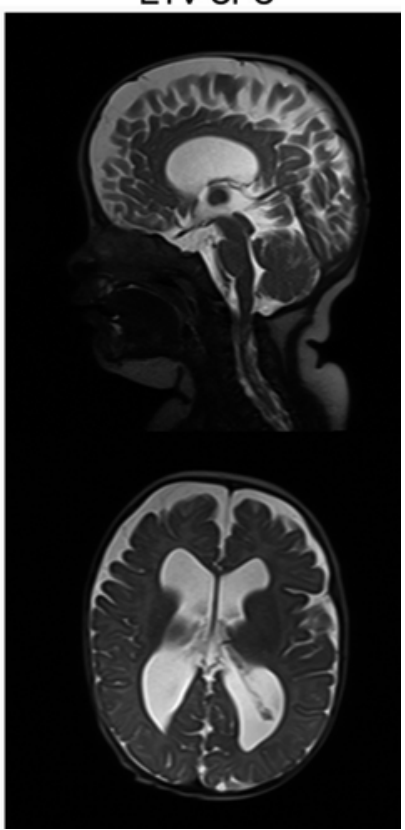

FIG. 3. Case 3. Studies obtained in a female fetus that showed postoperative HBH reversal after prenatal MMC repair at an EGA of $23+0$ weeks, with subsequent development of gradual-onset postnatal HCP and head circumference enlargement, requiring ETVICPC at 5 months of age.

could be differences in the anatomical integrity of the aqueductal region. Preoperative imaging before ETV treatment in our 2 cases of gradual-onset postnatal HCP was suggestive of, but indeterminate for, aqueductal stenosis owing to the limited quality of imaging at the time. Therefore, a contributory component to HCP evolution by stenosis at the aqueduct cannot be ruled out and is in fact supported by the observed response to ETV/CPC intervention in both cases. A fine-detailed MRI of the aqueduct would address this question, but it often requires anesthesia in the infant patient, and prospective efforts should carefully consider the benefits of doing so.

The clinical relevance of our series is 2 cases of prenatal MMC repair with complete $\mathrm{HBH}$ reversal in which gradual-onset HCP developed, requiring intervention. Although we cannot be certain of the exact mechanism by which this develops at this point in time, we speculate that possible predisposing features, including persistent ventriculomegaly and other ventricular abnormalities after MMC repair, as well as more cephalad defect locations, may affect long-term CSF hydrodynamics after delivery. ${ }^{6,14}$ It has also been suggested that MMC lesions below L2 are the most amenable to postnatal HCP risk reduction after prenatal repair. ${ }^{24}$ Although we note that in our series all postnatal HCP cases only occurred at the L2 level and not below, we require more cases to convincingly validate such a proposal. Nevertheless, our anecdotal experience emphasizes the importance of long-term HCP surveillance in neonates with a history of prenatal MMC repair to ensure that possible $\mathrm{HCP}-$ related complications are minimized, with the viable possibility that lesion level predicts success.

There are limitations to this institutional series. First, we acknowledge the cohort size is small. However, in its current form, it was large enough to demonstrate that prenatal $\mathrm{HBH}$ reversal after MMC repair does not necessarily eliminate completely the risk of postnatal HCP. A greater cohort size will assist in validating the true natural incidence in this particular demographic, as well as if there exist prognostic differences between immediate- and gradual-onset postnatal HCP. Second, the relationships between serial imaging parameters both before and after surgery and delivery may serve as useful correlates to each other and assist in clarification of how CSF hydrodynamics may be altered to lead to gradual-onset postnatal HCP. ${ }^{21}$ However, this will require greater numbers to achieve statistical power. In addition, we appreciate that our surveillance is an active process and that some patients in this cohort may be too young to completely discount the evolution of late gradual-onset HCP, possibly underestimating the true incidence of this phenomenon. Finally, longer-term follow-up will provide insight into the longevity of the postnatal HCP risk after surgery, because the question of whether or not this risk persists as long as the CSF system is developing throughout childhood remains unanswered and a concern.

\section{Conclusions}

We present an institutional series that highlights the observation that, despite early complete $\mathrm{HBH}$ reversal with 
prenatal MMC repair, there remains a risk of postnatal gradual-onset HCP developing in neonates within the 1st year of life and requiring intervention. The exact etiology and sequence of events remain unclear, although altered CSF hydrodynamics is possibly involved. Given the negative impact postnatal HCP can have on the quality of life of neonates as they develop, rigorous surveillance is recommended for all patients who have undergone prenatal MMC repair to ensure that such an impact is minimized and ideally prevented, irrespective of $\mathrm{HBH}$ outcome. A greater cohort size and longer follow-up period will enable us to develop more granular expectations about this phenomenon so as to improve postnatal surveillance after prenatal MMC repair.

\section{References}

1. Adzick NS, Thom EA, Spong CY, Brock JW III, Burrows PK, Johnson MP, et al: A randomized trial of prenatal versus postnatal repair of myelomeningocele. $\mathbf{N}$ Engl J Med 364:993-1004, 2011

2. Babcook CJ, Goldstein RB, Barth RA, Damato NM, Callen PW, Filly RA: Prevalence of ventriculomegaly in association with myelomeningocele: correlation with gestational age and severity of posterior fossa deformity. Radiology 190:703707, 1994

3. Beuriat PA, Szathmari A, Rousselle C, Sabatier I, Di Rocco F, Mottolese C: Complete reversibility of the Chiari Type II malformation after postnatal repair of myelomeningocele. World Neurosurg 108:62-68, 2017

4. Bouchard S, Davey MG, Rintoul NE, Walsh DS, Rorke LB, Adzick NS: Correction of hindbrain herniation and anatomy of the vermis after in utero repair of myelomeningocele in sheep. J Pediatr Surg 38:451-458, 2003

5. Boulet SL, Yang Q, Mai C, Kirby RS, Collins JS, Robbins JM, et al: Trends in the postfortification prevalence of spina bifida and anencephaly in the United States. Birth Defects Res A Clin Mol Teratol 82:527-532, 2008

6. Bruner JP, Tulipan N, Reed G, Davis GH, Bennett K, Luker KS, et al: Intrauterine repair of spina bifida: preoperative predictors of shunt-dependent hydrocephalus. Am J Obstet Gynecol 190:1305-1312, 2004

7. Caldarelli M, Di Rocco C, La Marca F: Shunt complications in the first postoperative year in children with meningomyelocele. Childs Nerv Syst 12:748-754, 1996

8. Cesmebasi A, Loukas M, Hogan E, Kralovic S, Tubbs RS, Cohen-Gadol AA: The Chiari malformations: a review with emphasis on anatomical traits. Clin Anat 28:184-194, 2015

9. Copp AJ, Adzick NS, Chitty LS, Fletcher JM, Holmbeck GN, Shaw GM: Spina bifida. Nat Rev Dis Primers 1:15007, 2015

10. Elbabaa SK, Gildehaus AM, Pierson MJ, Albers JA, Vlastos EJ: First 60 fetal in-utero myelomeningocele repairs at Saint Louis Fetal Care Institute in the post-MOMS trial era: hydrocephalus treatment outcomes (endoscopic third ventriculostomy versus ventriculo-peritoneal shunt). Childs Nerv Syst 33:1157-1168, 2017

11. Geerdink N, van der Vliet T, Rotteveel JJ, Feuth T, Roeleveld N, Mullaart RA: Essential features of Chiari II malformation in MR imaging: an interobserver reliability study-part 1. Childs Nerv Syst 28:977-985, 2012

12. Grivell RM, Andersen C, Dodd JM: Prenatal versus postnatal repair procedures for spina bifida for improving infant and maternal outcomes. Cochrane Database Syst Rev (10):CD008825, 2014

13. Heffez DS, Aryanpur J, Rotellini NA, Hutchins GM, Freeman JM: Intrauterine repair of experimental surgically created dysraphism. Neurosurgery 32:1005-1010, 1993

14. Khalil A, Caric V, Papageorghiou A, Bhide A, Akolekar R,
Thilaganathan B: Prenatal prediction of need for ventriculoperitoneal shunt in open spina bifida. Ultrasound Obstet Gynecol 43:159-164, 2014

15. Kulkarni AV, Sgouros S, Constantini S: International Infant Hydrocephalus Study: initial results of a prospective, multicenter comparison of endoscopic third ventriculostomy (ETV) and shunt for infant hydrocephalus. Childs Nerv Syst 32:1039-1048, 2016

16. McLone DG, Knepper PA: The cause of Chiari II malformation: a unified theory. Pediatr Neurosci 15:1-12, 1989

17. Meuli M, Meuli-Simmen C, Hutchins GM, Yingling CD, Hoffman KM, Harrison MR, et al: In utero surgery rescues neurological function at birth in sheep with spina bifida. Nat Med 1:342-347, 1995

18. Mitchell LE, Adzick NS, Melchionne J, Pasquariello PS, Sutton LN, Whitehead AS: Spina bifida. Lancet 364:1885-1895, 2004

19. Moldenhauer JS, Soni S, Rintoul NE, Spinner SS, Khalek N, Martinez-Poyer J, et al: Fetal myelomeningocele repair: the post-MOMS experience at the Children's Hospital of Philadelphia. Fetal Diagn Ther 37:235-240, 2015

20. Paek BW, Farmer DL, Wilkinson CC, Albanese CT, Peacock W, Harrison MR, et al: Hindbrain herniation develops in surgically created myelomeningocele but is absent after repair in fetal lambs. Am J Obstet Gynecol 183:1119-1123, 2000

21. Phillips BC, Gelsomino M, Pownall AL, Ocal E, Spencer HJ, O'Brien MS, et al: Predictors of the need for cerebrospinal fluid diversion in patients with myelomeningocele. J Neurosurg Pediatr 14:167-172, 2014

22. Sutton LN, Adzick NS, Bilaniuk LT, Johnson MP, Crombleholme TM, Flake AW: Improvement in hindbrain herniation demonstrated by serial fetal magnetic resonance imaging following fetal surgery for myelomeningocele. JAMA 282:1826-1831, 1999

23. Tulipan N, Bruner JP, Hernanz-Schulman M, Lowe LH, Walsh WF, Nickolaus D, et al: Effect of intrauterine myelomeningocele repair on central nervous system structure and function. Pediatr Neurosurg 31:183-188, 1999

24. Tulipan N, Sutton LN, Bruner JP, Cohen BM, Johnson M, Adzick NS: The effect of intrauterine myelomeningocele repair on the incidence of shunt-dependent hydrocephalus. Pediatr Neurosurg 38:27-33, 2003

25. Williams B: Chronic herniation of the hindbrain. Ann R Coll Surg Engl 63:9-17, 1981

26. Zarutskie A, Guimaraes C, Yepez M, Torres P, Shetty A, Sangi-Haghpeykar H, et al: Prenatal brain imaging for predicting need for postnatal hydrocephalus treatment in fetuses that had neural tube defect repair in utero. Ultrasound Obstet Gynecol 53:324-334, 2019

\section{Disclosures}

The authors report no conflict of interest concerning the materials or methods used in this study or the findings specified in this paper.

\section{Author Contributions}

Conception and design: Ahn, Lu, Snyder, Daniels. Acquisition of data: Ahn, Lu, Snyder, Ibirogba. Analysis and interpretation of data: all authors. Drafting the article: Ahn, Lu, Snyder, Ibirogba, Daniels. Critically revising the article: Ahn, Lu, Snyder, Ruano, Daniels. Reviewed submitted version of manuscript: all authors. Approved the final version of the manuscript on behalf of all authors: Ahn. Study supervision: Ahn.

\section{Correspondence}

Edward S. Ahn: Mayo Clinic, Rochester, MN. ahn.edward@mayo. edu. 